\title{
Deposition of Highly Porous Nanocrystalline Platinum on Functionalized Substrates Through Fluorine-Induced Decomposition of $\mathrm{Pt}_{(}\left(\mathrm{PF}_{3}\right)_{4}$ Adsorbates

\author{
Steven J. Randolph, ${ }^{*}, \dagger$ Aurelien Botman, ${ }^{\dagger}$ and Milos Toth ${ }^{\ddagger}$
}

FEI Company, 5350 NE Dawson Creek Drive, Hillsboro, OR 97214-5793 USA, and School of Physics and Advanced

Materials, University of Technology, Sydney, P.O. Box 123, Broadway, New South Wales 2007, Australia

Received July 18, 2013; E-mail: steven.randolph@fei.com

Highly porous, nanostructured platinum ${ }^{1-5}$ has numerous applications in fuel cell technology, ${ }^{4,6,7}$ gas sensing, ${ }^{8,9}$ heterogeneous catalysis ${ }^{10,11}$ and neurostimulation. ${ }^{12,13}$ Most favorable properties arise from a combination of high catalytic activity and large surface-to-volume ratio. Pt synthesis methods ${ }^{1,2}$ include chemical reduction (e.g., electrochemical, photochemical, sonochemical and radiolytic), thermal decomposition, ligand displacement from organometallics, hydrothermal growth, the sol-gel process, gasmediated electron, ${ }^{14,15}$ ion ${ }^{15}$ and laser ${ }^{16}$ beam induced deposition, laser ablation, chemical vapor deposition, and thermal evaporation. Porous platinum may also be produced ${ }^{1}$ using dealloying methods and by chemical plating ${ }^{17}$ or physical vapor deposition ${ }^{18}$ onto a pre-existing, high porosity framework. Fabrication of porous $\mathrm{Pt}$ electrodes in device structures often requires additional processing steps such as fixation, screen or inkjet printing, spraying or casting of Pt nanocrystallites. ${ }^{1}$

Here we demonstrate a fluorine mediated process for the decomposition of gaseous $\mathrm{Pt}\left(\mathrm{PF}_{3}\right)_{4}$ into porous platinum comprised of nanocrystallites with a diameter of $\sim 3 \mathrm{~nm}$ and the morphological structure ${ }^{19-22}$ of Pt black and Pt sponge. Film growth is achieved by flowing $\mathrm{Pt}\left(\mathrm{PF}_{3}\right)_{4}$ and $\mathrm{XeF}_{2}$ vapors over a solid substrate in vacuum. The Pt nucleation time scales with the coverage of fluorine supplied through dissociative chemisorption of $\mathrm{XeF}_{2}$. Subsequent, rapid film growth is autocatalyzed by highly pure, growing Pt nanocrystallites. Fluorine coverage is controlled by pre-dosing the substrate with $\mathrm{XeF}_{2}$ and by optional, concurrent irradiation using an electron beam or an ion beam. The beams can be used to limit Pt nucleation to regions that are functionalized through locally enhanced fluorination, and to direct write Pt pads onto complex substrates such as metal-oxide composites used in device structures.

Benefits of the fabrication technique described here stem from the fact that it is rapid, solvent-free, does not require heating, pressurization, sonication or electrical connections, and produces gas phase byproducts which desorb rapidly during growth. The beam directed localization process is analogous to electron beam induced deposition (EBID) and ion beam induced deposition (IBID) which entail decomposition of surface-adsorbed growth precursors such as $\mathrm{Pt}\left(\mathrm{PF}_{3}\right)_{4}$ directly by the beams rather than by fluorine. However, EBID and IBID are many orders of magnitude slower than the technique presented here, and typically yield highly impure deposits. ${ }^{14,15,23-26}$

Film growth was achieved by injecting $\mathrm{Pt}\left(\mathrm{PF}_{3}\right)_{4}$ and $\mathrm{XeF}_{2}$ vapors simultaneously into a vacuum chamber equipped with a coincident focused $\mathrm{Ga}$ ion beam and a scanning electron microscope (SEM). Figure 1A shows SEM images of gas injection capillaries used to mix the precursors near a Si substrate (with a native oxide), and the time evolution of a film growing on the surface. Growth proceeds from the region of high $\mathrm{XeF}_{2}$ flux toward the $\mathrm{Pt}\left(\mathrm{PF}_{3}\right)_{4}$ capillary, indicating a fluorine-limited reaction rate (SEM was used

\section{${ }^{\dagger}$ FEI}

$\stackrel{+}{\ddagger}$ UTS for imaging, but growth also occurs in the absence of electron irradiation). The deposited film extends over one millimeter in the plane of the support, and has a thickness of several microns in the high gas flux region and tens of nanometers at the deposit periphery. Visual inspection of the Pt films revealed a dull-grey to nearly black appearance. Atomic force microscopy (AFM) topographic maps (Figure 1B) show a high degree of surface roughness and porosity at both the nano and micro scales.

The composition of the $\mathrm{Pt}\left(\mathrm{PF}_{3}\right)_{4}+\mathrm{XeF}_{2}$ reaction product was compared to that of high purity reference $\mathrm{Pt}$, and impure nanocrystalline $\mathrm{Pt}$ fabricated by EBID using $\mathrm{Pt}\left(\mathrm{PF}_{3}\right)_{4}$ as the precursor gas ${ }^{27-31}$ (in the absence of $\mathrm{XeF}_{2}$ ). EBID typically produces materials with a high concentration of impurities comprised of precursor ligand constituents, and residual molecules such as $\mathrm{H}_{2} \mathrm{O}$ and $\mathrm{O}_{2}$ present in the vacuum chamber. ${ }^{14,15,23-26}$ This issue is evidenced by the energy dispersive $\mathrm{x}$-ray spectroscopy (EDS) data shown in Figure 1B. The EBID-grown film contains $\mathrm{P}, \mathrm{F}$ and $\mathrm{O}$ impurities. ${ }^{32}$ In contrast, the spectrum from the film grown by mixing $\mathrm{Pt}\left(\mathrm{PF}_{3}\right)_{4}$ with $\mathrm{XeF}_{2}$ is indistinguishable from that of the reference, high purity Pt sample.

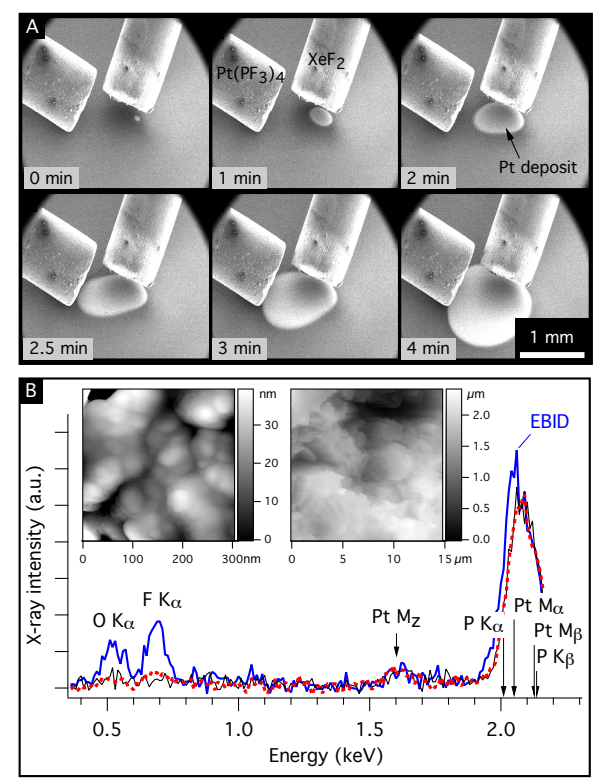

Figure 1. A) Time lapse sequence of SEM images showing gas delivery capillaries and $\mathrm{Pt}$ growth on a $\mathrm{Si}$ substrate. B) AFM topographic maps and an EDS spectrum of the $\mathrm{Pt}\left(\mathrm{PF}_{3}\right)_{4}+\mathrm{XeF}_{2}$ reaction product $(\cdots \cdots)$. The spectrum is compared to those of a reference, high purity $\mathrm{Pt}$ sample (- ), and Pt deposited using EBID (-). The spectra are normalized to emphasize compositional differences between the three materials. Arrows show nominal x-ray line positions.

Critically, a conditioning period of at least 30 to 45 minutes of $\mathrm{XeF}_{2}$ flow was needed at the start of each experimental session to achieve reproducible $\mathrm{Pt}$ nucleation behavior during simultaneous $\mathrm{Pt}\left(\mathrm{PF}_{3}\right)_{4}$ and $\mathrm{XeF}_{2}$ flow. ${ }^{33}$ This prerequisite is attributed to fluori- 
nation of the substrate through activated dissociative chemisorption of $\mathrm{XeF}_{2}$, and the need for a fluorine-rich stoichiometry to achieve complete decomposition of $\mathrm{Pt}\left(\mathrm{PF}_{3}\right)_{4}$ adsorbates. It is well known ${ }^{34-36}$ that $\mathrm{XeF}_{2}$ dissociates on many surfaces, generating $\mathrm{Xe}$ (which desorbs rapidly) and chemisorbed fluorine, and that the fluorine concentration takes tens of minutes to saturate and reach one monolayer on $\mathrm{SiO}_{2}{ }^{37}$ at room temperature. It is also well established that electron exposure causes dissociation of $\mathrm{XeF}_{2}$ adsorbates, and that the resulting fluorine can chemisorb to the substrate. ${ }^{38}$ It is therefore reasonable to expect that electron beam preexposure of a substrate in an $\mathrm{XeF}_{2}$ environment may increase the fluorine coverage and localize Pt film growth. To test this hypothesis, three $50 \mu \mathrm{m}$ partially overlapping circles were patterned in parallel on the native oxide of a Si substrate with an electron beam. The electron fluence was maintained sufficiently low to prevent removal of the oxide by electron beam induced etching ${ }^{38,39}$ and avoid rapid spontaneous ${ }^{34,35} \mathrm{XeF}_{2}$ etching of the Si. Following pre-patterning, the beam was blanked, $\mathrm{Pt}\left(\mathrm{PF}_{3}\right)_{4}$ was injected into the chamber, and the precursors were flown simultaneously for $\sim 60 \mathrm{~s}$. The substrate was imaged using secondary electrons and the $\mathrm{Pt} \mathrm{M}_{\alpha}$ and $\mathrm{Si} \mathrm{K}_{\alpha} \mathrm{X}$ ray lines (Figure $2 \mathrm{~A}$ ) immediately after cessation of precursor flow. Clearly, the Pt deposited only in regions that had been pre-patterned by the beam, and the quantity of Pt scales with pre-exposure electron fluence.

It is important to emphasize that the beam-induced-fluorination process reduces the Pt nucleation time, but the subsequent deposition rate is constant and independent of the electron fluence. The contrast in the Pt $\mathrm{M}_{\alpha}$ map seen in Figure $2 \mathrm{~A}$ is caused by corresponding variations in nucleation time and hence the net $\mathrm{Pt}$ growth time. Film localization was maintained by making the $\mathrm{XeF}_{2}$ partial pressure sufficiently low to delay nucleation in regions that had not been pre-patterned beyond the total Pt deposition time. After nucleation, rapid, localized Pt growth was observed, indicative of an autocatalytic process mediated by high purity Pt. Conversely, all attempts at localization failed when $\mathrm{Pt}\left(\mathrm{PF}_{3}\right)_{4}$ and $\mathrm{XeF}_{2}$ were flown over substrates that contained deposits which had been pre-grown by EBID. This is consistent with the EDS spectra in Figure 1B which show that the EBID-grown material contains impurities that likely inhibit Pt growth autocatalysis.

Localized deposition of the highly pure Pt films can also be achieved by scanning a substrate while $\mathrm{Pt}\left(\mathrm{PF}_{3}\right)_{4}$ and $\mathrm{XeF}_{2}$ are delivered to the vacuum chamber. A Pt pad grown using this approach is shown in Figure 2B where the substrate is a metal-oxide composite comprised of thermal $\mathrm{SiO}_{2}$ and $\mathrm{Cr}$ electrodes. The $\mathrm{Pt}$ pad was grown by scanning a $35 \mu \mathrm{m} \times 7.5 \mu \mathrm{m}$ region with a $286 \mathrm{pA}, 30 \mathrm{keV}$ electron beam for 40 minutes under a flowing mixture of $\mathrm{Pt}\left(\mathrm{PF}_{3}\right)_{4}$ and $\mathrm{XeF}_{2}$. The beam was maintained scanning during Pt deposition, but the electron flux was sufficiently low to make the direct EBID rate ${ }^{14,15,23,24,27-31}$ negligible. The deposit is highly pure (i.e., indistinguishable from pure $\mathrm{Pt}$ within the detection limits of EDS), and exhibits porosity that spans nano- to microscopic length scales. The structure seen in the scanning transmission electron microscopy (STEM) images in Figure 2C-D is consistent with the AFM profiles in Figure 1B. It is analogous to that of Pt black and Pt sponge, ${ }^{19-22}$ and distinctly different from that of the comparatively smooth, continuous EBID-grown Pt. ${ }^{27-31}$ Transmission electron microscopy (TEM) images and selected area diffraction (SAD) patterns show that the material is nanocrystalline, fcc Pt with a crystallite diameter of $\sim 3 \mathrm{~nm}$ (Figure 2E). Cracks such as those seen in Figure $2 \mathrm{C}$ and $\mathrm{D}$ were observed in thick films and are attributed to relaxation of high residual stresses in the deposits. Film growth took place at high rates and room temperature, where adatom mobility is low and can result in high film stresses that increase with film thickness. Film stress is typically concentrated at defects sim- ilar to the pores, which likely mediate crack propagation through the deposits.

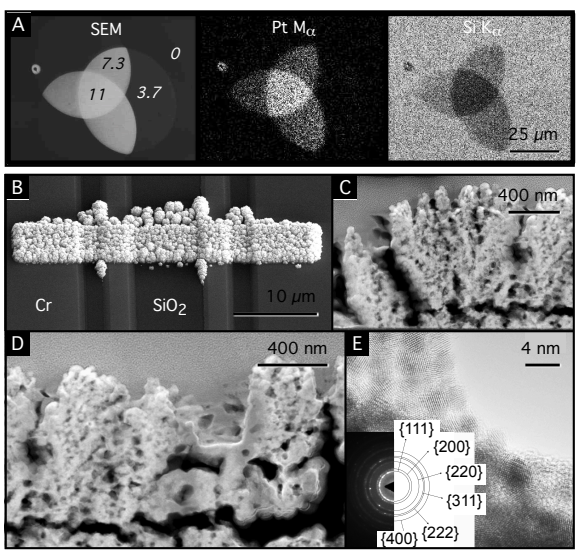

Figure 2. A) SEM image and EDS maps of Pt deposits grown on three prepatterned circular, overlapping surface regions. The mean pre-patterning fluence was 11, 7.3, 3.7 and 0 electrons $/ \AA^{2}$. B) An SEM image, (C,D) STEM images, and (E) a TEM image and a SAD pattern of a Pt deposit grown on a substrate comprised of $\mathrm{SiO}_{2}$ and $\mathrm{Cr}$ electrodes.

Pt film localization was also achieved by $30 \mathrm{keV} \mathrm{Ga}^{+}$beam preexposure of the substrates under flowing $\mathrm{XeF}_{2}$. This is not surprising since ion irradiation causes adsorbate dissociation ${ }^{38}$ in a manner analogous to electron irradiation. The process is, however, complicated by ion induced surface roughening and amorphization, and is therefore not discussed here in detail.

We now turn to an analysis of the surface functionalization (i.e., fluorination) process which leads to $\mathrm{Pt}$ nucleation and enables beam directed localization. A mixture of $\mathrm{XeF}_{2}$ and $\mathrm{Pt}\left(\mathrm{PF}_{3}\right)_{4}$ is expected to decompose to solid $\mathrm{Pt}$ and gaseous byproducts through fluorineinduced decomposition of $\mathrm{Pt}\left(\mathrm{PF}_{3}\right)_{4}$ and thermal desorption of $\mathrm{Xe}$ and $\mathrm{PF}_{\mathrm{X}}$ adsorbates ${ }^{40-42}$ (where the desorption rate increases as $\mathrm{X}$ is increased from 3 to 5). To show that the experimental Pt nucleation time scales with calculated reciprocal concentration of adsorbed $\mathrm{F}$, we used a model of $\mathrm{XeF}_{2}$ adsorption and dissociation in the presence of energetic electrons. It is based on a general model of physisorption and activated chemisorption ${ }^{43}$ which we adapted for the case of $\mathrm{XeF}_{2}$ molecules on $\mathrm{SiO}_{2}$ as described in the Supporting Information.

Figure $3 \mathrm{~A}$ is a schematic illustration of the physisorbed $\mathrm{XeF}_{2}$ and chemisorbed $\mathrm{F}$ states considered by the model. The reaction coordinate is distance away from the substrate surface, and fluorination is assumed to proceed primarily through dissociation of physisorbed $\mathrm{XeF}_{2}$ molecules as discussed in the Supporting Information. Parts $\mathrm{B}$ and $\mathrm{C}$ of the figure show plots of $\mathrm{F}$ and $\mathrm{XeF}_{2}$ coverage (i.e., fractional occupation of the chemisorbed and physisorbed states, each limited to one monolayer). The coverages were calculated at room temperature as a function of time after the $\mathrm{SiO}_{2}$ substrate is exposed to $\mathrm{XeF}_{2}$ vapor. The initial coverages were set to zero, and the times it takes $\mathrm{F}$ coverages to saturate represent reciprocal surface functionalization rates. 

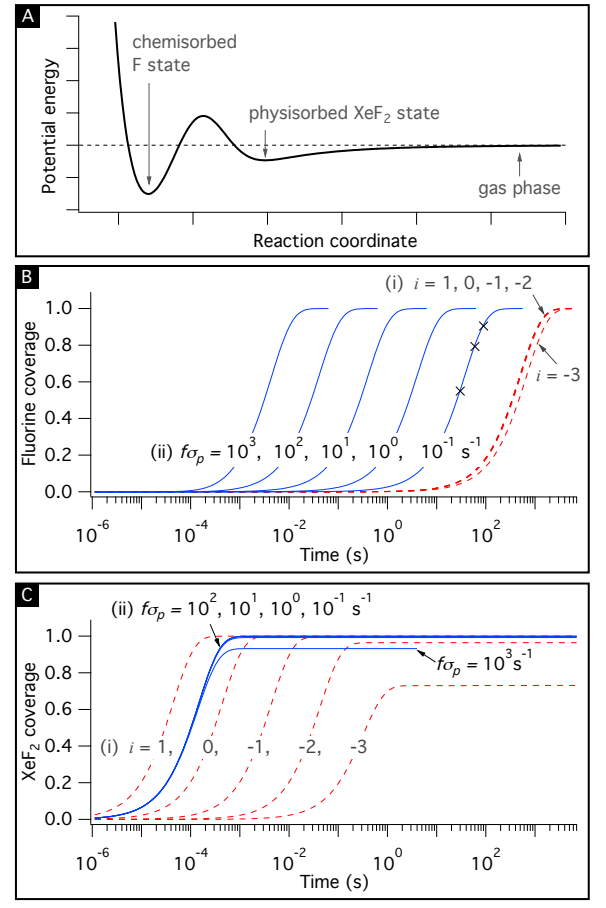

Figure 3. A) Schematic one dimensional potential energy diagram for $\mathrm{XeF}_{2}$ physisorption and activated chemisorption. $\left.\mathrm{B}, \mathrm{C}\right) \mathrm{F}$ and $\mathrm{XeF}_{2}$ coverage calculated as a function of time under these conditions: (i) no electron exposure [(- - -), $s_{p} P=1.3 \times 10^{i} \mathrm{~Pa}$, where $i=-3$ to 1 step 1], and (ii) with electron dissociation of $\mathrm{XeF}_{2}$ enabled [ $(-), f \sigma_{p}=10^{-1}$ to $10^{3} \mathrm{~s}^{-1}$; $\left.s_{p} P=4 \mathrm{~Pa}\right]$. Markers $(\times)$ indicate $\mathrm{F}$ coverage at electron beam exposure times of 30,60 and $90 \mathrm{~s}\left[f \sigma_{p}=10^{-1} \mathrm{~s}^{-1}\right]$.

Beam-free functionalization was simulated using $s_{p} P$ values in the range of $10^{-3}$ to $10 \mathrm{~Pa}$, where $s_{p}$ is the sticking coefficient for $\mathrm{XeF}_{2}$ physisorption, $P$ is pressure and the $s_{p} P$ values encompass the range encountered in our experiments, as discussed in the Supporting Information. Chemisorbed $\mathrm{F}$ coverage takes thousands of seconds to saturate at all pressures considered in the calculations (see the curves labelled (i) in Figure 3B). Conversely, the $\mathrm{XeF}_{2}$ coverage saturation time is much shorter $\left(10^{-4}\right.$ to $1 \mathrm{~s}$; Figure $\left.3 \mathrm{C}\right)$ and a strong function of pressure. This behavior is expected since $\mathrm{XeF}_{2}$ physisorption is rate-limited by the gas molecule arrival rate from vacuum, and the physisorbed $\mathrm{XeF}_{2}$ coverage rapidly saturates at each pressure. The chemisorption rate is slower because it is limited by dissociation of $\mathrm{XeF}_{2}$ molecules, which is governed primarily by the height of the activation barrier between the physisorbed and chemisorbed states shown in Figure 3A.

Electron beam functionalization was simulated using $f \sigma_{p}$ values in the range of $10^{-1}$ to $10^{3} \mathrm{~s}^{-1}$, where $f$ is electron flux and $\sigma_{p}$ is the effective cross-section for electron dissociation of physisorbed $\mathrm{XeF}_{2}$ molecules. The model shows that electron irradiation causes a dramatic decrease in the fluorination time, even under conditions of very low electron flux (see the curves labelled (ii) in Figure 3B). Hence, electron beam exposure of $\mathrm{SiO}_{2}$ in an $\mathrm{XeF}_{2}$ environment is expected to cause very efficient, rapid fluorination of the surface. An example that we can compare to experiment is provided by the curve calculated using $f \sigma_{p}=10^{-1} \mathrm{~s}^{-1}$, which approximates the conditions used to generate the partially overlapping circles in Figure 2A. The curve yields $\mathrm{F}$ coverages of $\sim 0.55,0.79$ and 0.91 at exposure times of 30,60 and $90 \mathrm{~s}$, respectively. These times correspond to the three regions of zero, single and double overlap which are seen in Figure 2A as regions of progressively elevated Pt concentration. The correlation between measured Pt concentration (Figure 2A) and calculated $F$ coverage (markers $(\times)$ in Figure $3 \mathrm{~B}$ ) is consistent with the interpretation that the $\mathrm{Pt}$ nucleation time scales with reciprocal fluorine coverage.

The data in Figure 3B also show that the measured Pt concentration does not scale with physisorbed $\mathrm{XeF}_{2}$ coverage. At electron fluxes used in the experiments, $\mathrm{XeF}_{2}$ coverage is governed by the $\mathrm{XeF}_{2}$ adsorption rate from the gas phase. At very high electron fluxes $\left(f \sigma_{p} \gtrsim 10^{3} \mathrm{~s}^{-1}\right)$, the coverage decreases with $f$ (due to rapid consumption of $\mathrm{XeF}_{2}$ through electron induced dissociation) and can not explain the nucleation behavior observed experimentally.

The above simulation results are consistent with the hypothesis that Pt nucleation is induced by chemisorbed fluorine. Both the theory and experiments indicate that the beam-free growth process is scalable and can potentially be used for deposition of large area films by controlled, uniform delivery of $\mathrm{Pt}\left(\mathrm{PF}_{3}\right)_{4}$ and $\mathrm{XeF}_{2}$ to macroscopic substrates. The process is solvent-free, applicable to both conducting and insulating substrates and occurs at room temperature. It is therefore compatible with a wide range of substrates, as well as photoresist microfabrication and lift-off techniques that are typically used for lithography of wafer-scale electrodes. Substrates may optionally be functionalized by (delocalized) electron flood exposure, or using a highly focused electron beam. The former may improve the throughput of large area deposition, while the latter enables direct-writing of Pt for nano-prototyping. The autocatalysis of Pt growth observed after nucleation suggests that the as-grown films and nanoparticles are well suited to a wide range of applications.

In summary, we developed a method for the synthesis of highly porous, nanocrystalline platinum based on fluorine-induced decomposition of $\mathrm{Pt}\left(\mathrm{PF}_{3}\right)_{4}$ adsorbates. Spatial localization was achieved by functionalizing substrates by charged particle beams. The Pt nucleation time was shown to scale with reciprocal fluorine coverage by a combination of experiment and a rate kinetics model of $\mathrm{XeF}_{2}$ dissociation on $\mathrm{SiO}_{2}$.

\section{Experimental Section}

Pt deposition was carried out in a FEI Company Quanta 3D field emission gun (FEG) Dual Beam modified to enable simultaneous delivery of $\mathrm{XeF}_{2}$ and $\mathrm{Pt}\left(\mathrm{PF}_{3}\right)_{4}$ vapors into the specimen chamber. The solid $\mathrm{XeF}_{2}$ and liquid $\mathrm{Pt}\left(\mathrm{PF}_{3}\right)_{4}$ precursors were housed externally in separate stainless steel vapor delivery systems equipped with pressure-feedback motorized leak valves that enable accurate, independent control of precursor flow rates into the vacuum chamber. Each vapor was routed independently to a gas injection capillary with an inner diameter of $500 \mu \mathrm{m}$, that could be positioned freely during SEM imaging (Figure 1A). The gases were not premixed and interacted only after exiting their respective capillaries. Three substrates were used to investigate the deposition process: $\mathrm{Si}$ with a native oxide, thermally grown $\mathrm{SiO}_{2}$, and $\mathrm{SiO}_{2}$ with prepatterned $\mathrm{Cr}$ electrodes. Typical background partial pressures of $\mathrm{Pt}\left(\mathrm{PF}_{3}\right)_{4}$ and $\mathrm{XeF}_{2}$ were $\sim 10^{-3} \mathrm{~Pa}$ and $3 \times 10^{-3} \mathrm{~Pa}$, respectively. The corresponding maximum local pressures at the substrate surface were approximately three orders of magnitude greater than the background pressures. ${ }^{44} \mathrm{Pt}\left(\mathrm{PF}_{3}\right)_{4}$ has previosly been used as a precursor for chemical vapor deposition, ${ }^{42,45}$ laser beam deposition, ${ }^{16}$ and EBID. ${ }^{27-31}$ We performed EBID using a $5 \mathrm{keV}, 3.4 \mathrm{nA}$ electron beam.

SEM imaging and EDS analysis were done in-situ using an Everhart-Thornley secondary electron detector, and an Oxford Instruments INCA EDS system. Ex-situ analysis was performed on samples that had been transferred in air, using TEM, high angle annular dark field (HAADF) STEM and SAD using an FEI Titan. Lamella for TEM analysis were prepared using conventional 
ion beam preparation and liftout ${ }^{46}$ techniques. Surface morphology was characterized in air by tapping mode AFM performed with etched silicon probes installed on a Dimension DI-3100 AFM.

\section{Notes and References}

(1) Kloke, A.; von Stetten, F.; Zengerle, R.; Kerzenmacher, S. Adv. Mater 2011, 23, 4976-5008.

(2) Chen, A.; Holt-Hindle, P. Chem Rev 2010, 110, 3767-3804

(3) Attard, G. S.; Bartlett, P. N.; Coleman, N. R. B.; Elliott, J. M.; Owen, J. R.; Wang, J. H. Science 1997, 278, 838-840.

(4) Ding, Y.; Chen, M. W.; Erlebacher, J. J. Am. Chem. Soc. 2004, 126, 68766877.

(5) Kloke, A.; Koehler, C.; Gerwig, R.; Zengerle, R.; Kerzenmacher, S. Adv. Mater. 2012, 24, 2916-2921.

(6) Steele, B. C. H.; Heinzel, A. Nature 2001, 414, 345-352.

(7) Ralph, T. R.; Hogarth, M. P. Platinum Metals Rev 2002, 46, 3-14

(8) Korotcenkov, G.; Do Han, S.; Stetter, J. R. Chem Rev 2009, 109, 1402 1433.

(9) Stetter, J. R.; Li, J. Chem Rev 2008, 108, 352-366.

(10) Astruc, D.; Lu, F.; Aranzaes, J. R. Angew Chem Int Edit 2005, 44, 7852 7872 .

(11) Murzin, D. Y.; Maki-Arvela, P.; Toukoniitty, E.; Salmi, T. Catal Rev 2005 47, 175-256

(12) Mailley, S.; Hyland, M.; Mailley, P.; McLaughlin, J. A.; McAdams, E. T. Bioelectrochemistry 2004, 63, 359-364.

(13) Cheung, K. C. Biomed Microdevices 2007, 9, 923-938.

(14) Randolph, S. J.; Fowlkes, J. D.; Rack, P. D. Cr. Rev. Solid State 2006, 31 $55-89$.

(15) Utke, I.; Hoffmann, P.; Melngailis, J. J. Vac. Sci. Technol. B 2008, 26, 1197-1276.

(16) Schroder, H.; Kompa, K. L.; Masci, D.; Gianinoni, I. Appl Phys A-Mater 1985, 38, 227-233.

(17) Hayase, M.; Fujii, T.; Alves Brito-Neto, J. G. Journal of The Electrochemical Society 2011, 158, B355.

(18) Brault, P.; Caillard, a.; Thomann, a. L.; Mathias, J.; Charles, C.; Boswell, R. W.; Escribano, S.; Durand, J.; Sauvage, T. Journal of Physics D: Applied Physics 2004, 37, 3419-3423.

(19) Benton, A. F. J. Am. Chem. Soc. 1926, 48, 1850-1861.

(20) Feltham, A. M.; Spiro, M. Chem Rev 1971, 71, 177-193.

(21) Guo, S.; Fang, Y.; Dong, S.; Wang, E. J Phys Chem C 2007, 111, 17104 17109

(22) Marrese, C. A. Anal Chem 1987, 59, 217-218.

(23) Van Dorp, W. F.; Hagen, C. W. J. Appl. Phys. 2008, 104, 081301.

(24) Botman, A.; Mulders, J. J. L.; Hagen, C. W. Nanotechnology 2009, 20, 372001 .

(25) Utke, I.; Michler, J.; Gasser, P.; Santschi, C.; Laub, D.; Cantoni, M.; Buffat, P. A.; Jiao, C.; Hoffmann, P. Adv. Eng. Mater. 2005, 7, 323-331.

(26) Hoeflich, K.; Yang, R. B.; Berger, A.; Leuchs, G.; Christiansen, S. Adv Mater. 2011, 23, 2657-2661.

(27) Wang, S.; Sun, Y.-M. M.; Wang, Q.; White, J. M. J. Vac. Sci. Technol. B 2004, 22, 1803-1806.

(28) Barry, J. D.; Ervin, M.; Molstad, J ; Wickenden, A.; Brintlinger, T.; Hoffman, P.; Meingailis, J. J. Vac. Sci. Technol. B 2006, 24, 3165-3168.

(29) Botman, A.; Hesselberth, M.; Mulders, J. J. L. Microelectronic Engineer ing 2008, 85, 1139-1142.

(30) Botman, A.; Hagen, C. W.; Li, J.; Thiel, B. L.; Dunn, K. A.; Mulders, J. J. L.; Randolph, S.; Toth, M. J. Vac. Sci. Technol. B 2009, 27, 2759-2763.

(31) Landheer, K.; Rosenberg, S. G.; Bernau, L.; Swiderek, P.; Utke, I.; Hagen, C. W.; Fairbrother, D. H. J. Phys. Chem. C 2011, 115, 17452-17463.

(32) The $\mathrm{P} \mathrm{K}_{\alpha}$ peak overlaps with $\mathrm{Pt} \mathrm{M}_{\alpha}$, causing broadening of the low energy side of the net peak seen in the figure.

(33) The conditioning treatment had to be repeated each time gas flow was terminated and the chamber was left in high vacuum for more than $\sim 3$ hours, or if a vent cycle was performed, likely due to $\mathrm{F}$ interactions with $\mathrm{H}_{2} \mathrm{O}$ and $\mathrm{O}_{2}$

(34) Winters, H. F.; Coburn, J. W. Appl. Phys. Lett. 1979, 34, 70-73.

(35) Tu, Y. Y.; Chuang, T. J.; Winters, H. F. Phys. Rev. B 1981, 23, 823-835.

(36) Loudiana, M. A.; Schmid, A.; Dickinson, J. T.; Ashley, E. J. Surf. Sci. 1984, 141, 409-416.

(37) Hills, M. M.; Arnold, G. S. Appl. Surf. Sci. 1991, 47, 77-90.

(38) Coburn, J.; Winters, H. J. Appl. Phys. 1979, 50, 3189-3196.

(39) Randolph, S.; Toth, M.; Cullen, J.; Chandler, C.; Lobo, C. Appl. Phys. Lett. 2011, 99, 213103.

(40) Goldberg, I. B.; Crowe, H. R.; Pilipovich, D. Chem. Phys. Lett. 1975, 33 347-350.

(41) Nitschke, F.; Ertl, G.; Kuppers, J. J. Chem. Phys. 1981, 74, 5911-5921.

(42) Zhang, R.; Comita, P. B. Chem Phys Lett 1992, 200, 297-302.

(43) Bishop, J.; Lobo, C. J.; Martin, A.; Ford, M.; Phillips, M.; Toth, M. Phys. Rev. Lett. 2012, 109, 146103.

(44) Friedli, V.; Utke, I. J. Phys. D 2009, 42, 125305

(45) Rand, M. J. J. Electrochem. Soc. 1973, 120, 686-693.

(46) Giannuzzi, L.; Stevie, F. Micron 1999, 30, 197-204. 